\title{
Low voltage and high frequency vertical organic field effect transistor based on rod-coating silver nanowires grid electrode
}

\author{
Luiz G.S. Albano*, Miguel H. Boratto, Oswaldo Nunes-Neto, Carlos F.O. Graeff \\ São Paulo State University (Unesp), School of Sciences, Department of Physics, Bauru, 17033-360, Brazil
}

\section{A R T I C L E I N F O}

\section{Article history:}

Received 21 June 2017

Received in revised form

4 August 2017

Accepted 8 August 2017

Available online 12 August 2017

\section{Keywords:}

Silver nanowires

Vertical FETs

Vertical organic transistor

Transparent conductive electrodes

Mayer rod-coating

\begin{abstract}
A B S T R A C T
We report on low voltage and high frequency vertical organic field-effect transistors (VOFETs) using silver nanowires (AgNWs) as intermediate grid electrode (source) deposited through Mayer rod-coating. The optimized AgNWs electrodes deposited on insulator surface followed by low thermal annealing have sheet resistance of $\sim 30 \Omega / \mathrm{sq}$ and surface roughness of $70 \pm 20 \mathrm{~nm}$. Crosslinked poly(vinyl alcohol) is used as gate insulator and $C_{60}$ fullerene as n-type channel semiconductor. Our VOFETs have high output current density of $2.5 \mathrm{~mA} / \mathrm{cm}^{2}$ and on/off ratio of $5 \times 10^{3}$ with supply voltages up to $2 \mathrm{~V}$. A fast switching performance of sub-1 $\mu$ s at frequency gate modulation of $0.13 \mathrm{MHz}$ is demonstrated. Moreover, our devices are produced based on low-cost methods compatible with industrial-scale production of organic electronics.
\end{abstract}

(c) 2017 Elsevier B.V. All rights reserved.

\section{Introduction}

Transparent conductive electrodes (TCEs) based on nanostructured materials attract considerable interest in optoelectronics due to the combination of low sheet resistance $\left(R_{s h}\right)$, transparency and, in general, low processing costs [1]. In this way, several nanostructured materials such as carbon nanotubes, graphene, and metal nanowires were proposed as TCEs [2-4]. Among them, silver nanowires (AgNWs) are considered one of the most promising candidates due to their excellent electrical, mechanical, thermal and optical properties [5], especially as transparent electrodes in organic light-emitting diodes (OLEDs) and organic solar cells (OSCs) [6-8]. Moreover, they are also interesting for electronic devices where transparency to visible light is not fundamental, as is the case of intermediate electrodes in Vertical Organic Field Effect Transistors (VOFETs).

A VOFET is essentially a semiconductor diode stacked over a capacitor separated by a common intermediate electrode usually acting as source [9]. The device is governed by the sourcesemiconductor interface where the gate bias modulates the carrier density within the semiconductor due to the electrical field transparency of the intermediate electrode. Such transparency

\footnotetext{
* Corresponding author.

E-mail address: gustavoalbano@fc.unesp.br (L.G.S. Albano).
}

must arise without significant increase in the in-plane resistivity to ensure homogenous potential along the device [10].

Many different materials have been considered as intermediate electrodes in VOFETs, for example, ultra-thin evaporated metallic films are commonly used [9,11], but at low voltages, considerable shielding effects are observed, while source electrodes with random carbon nanotubes have demonstrated great electric permeability to the electric field but considerable high $\mathrm{R}_{\mathrm{sh}}(>\mathrm{k} \Omega / \mathrm{sq})$ [12]. Other alternatives using graphene either in horizontal or vertical heterostructures [13-15], block-copolymer templates [16], ultra-thin ITO films [17], and atomic layer deposition assisted nanoimprint lithography [18] have provided excellent performances, but their relatively high costs are not totally compatible with the potential advantages of the low production costs of VOFETs. Recently, thermally evaporated Sn thin films under controlled conditions were used and presented good performances at low voltages, however with low on/off ratios [10]. Metallic nanowires $(\mathrm{Ag} / \mathrm{Au})$ were used as intermediate electrode in the past with on/off ratios of $\sim 10^{5}$ at considerable high voltages [19], however, the method used based on solution-processed nanowires can be incompatible with common organic insulators.

To overcome these obstacles, in this work we report on a VOFET using AgNWs as intermediate grid electrode deposited through Mayer rod-coating, a simple and low-cost thin film deposition method. 


\section{Experimental details}

VOFETs were prepared depositing $80 \mathrm{~nm}$ thick $\mathrm{Al}$ as gate electrode by thermal evaporation at $8 \times 10^{-6}$ torr on previously cleaned glass substrates. The gate insulator was prepared based on previous

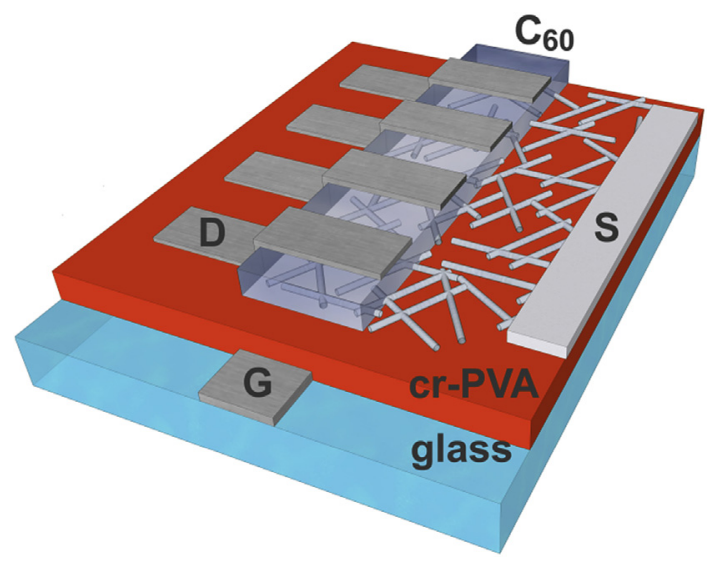

Fig. 1. 3D illustration of the $\mathrm{Al} / \mathrm{cr}-\mathrm{PVA} / \mathrm{AgNWs} / \mathrm{C}_{60} / \mathrm{Al}$ VOFET with $\mathrm{AgNW}$ intermediate grid electrode acting as source. work [20]. Poly(vinyl alcohol), PVA, purchased from Sigma-Aldrich (130 kDa) was used without further purification and dissolved in ultra-pure deionized water $(18.2 \mathrm{M} \Omega \mathrm{cm})$ at concentration of $60 \mathrm{mg} / \mathrm{ml}$. The PVA solution was then kept under stirring for $1 \mathrm{~h}$ at $60{ }^{\circ} \mathrm{C}$. In the sequence, ammonium dichromate (AD) from SynthBrazil (99.5\%) was added to the PVA solution at $25 \% \mathrm{w} / \mathrm{w}$ and filtered using $0.22 \mu \mathrm{m}$ pore filters (Merck Millipore). Then, the AD:PVA solution was deposited on the gate surface by spin coating at $3000 \mathrm{rpm}$ during $60 \mathrm{~s}$, followed by $12 \mathrm{~min}$ of UV treatment (365 nm, $8 \mathrm{~W}$ ) resulting in $\sim 350 \mathrm{~nm}$ thick crosslinked PVA (cr-PVA) film. Next, the cr-PVA thin film was annealed at $110{ }^{\circ} \mathrm{C}$ in an oven for $1 \mathrm{~h}$. As intermediate electrode, AgNWs from ACS Material (MA, USA) with $299.5 \%$ purity, $40 \mathrm{~nm}$ of diameter and length of about 20-30 $\mu \mathrm{m}$ was diluted in isopropyl alcohol (IPA) to form a suspension of $5 \mathrm{mg} / \mathrm{ml}$. The grid electrode was deposited on cr-PVA surface of $2.5 \mathrm{~cm} \times 1.5 \mathrm{~cm}$ area using a wire-wound rod (Mayer rod)-coating \# 10 purchased from R. D. Specialties (NY, USA). For each of the 4 layers in our devices, $40 \mu \mathrm{L}$ of AgNWs suspension was used. An interval of 5 min was taken between each AgNWs layer to assure IPA evaporation. After all AgNWs layers were deposited, the sample was annealed during $40 \mathrm{~min}$ on a hot plate in air at $120^{\circ} \mathrm{C}$ to remove the oxidation layer and increase the contact between AgNWs junctions [21]. Then, $120 \mathrm{~nm}$ of $\mathrm{C}_{60}$ fullerene (n-type semiconductor) from Sigma-Aldrich was deposited by thermal
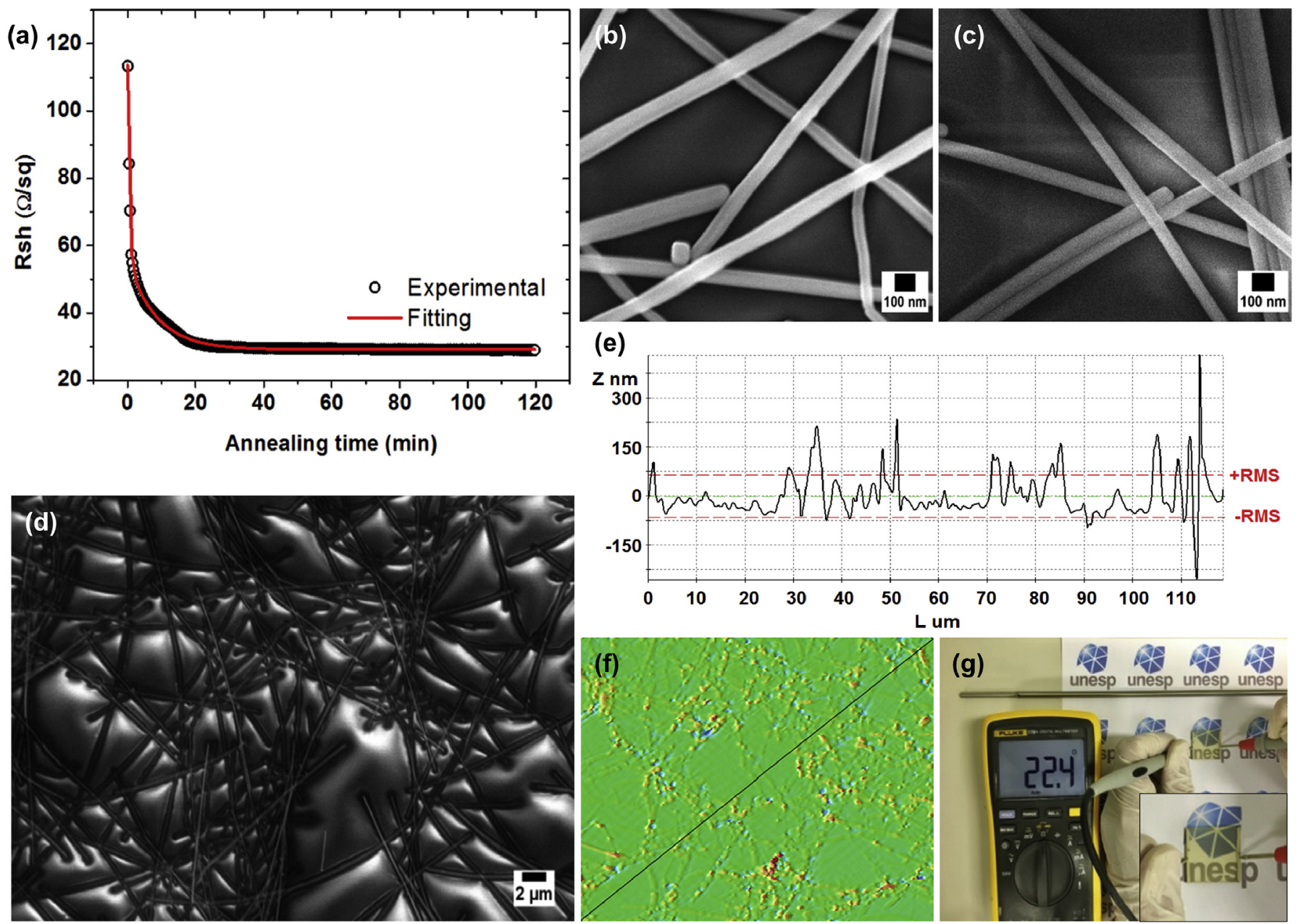

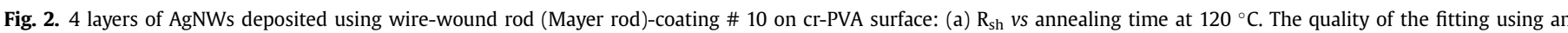

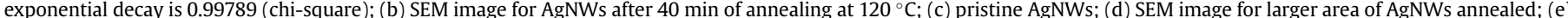

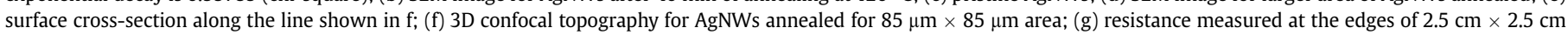
AgNWs electrode after annealing, lateral contacts were made with silver paint. Same annealing in b was used for $d$, e, $f$, and $g$. 
evaporation at $8 \times 10^{-6}$ torr with a deposition rate of $\sim 0.5 \mathrm{~nm} / \mathrm{s}$. Finally, as drain electrode, an $80 \mathrm{~nm}$ thick $\mathrm{Al}$ electrode was evaporated resulting in VOFETs with gate and drain overlap of $4 \mathrm{~mm}^{2}$. Fig. 1 shows the final device structure.

Silver nanowires grid electrodes were morphologically characterized using confocal (Leica DCM 3D) and FEG-SEM (Jeol 7500F) microscopes. Sheet resistance was measured using the four-point van der Pauw method with a source-measurement unit Keithley 2400C. PVA and cr-PVA were characterized using thermogravimetric analysis (Netzsch STA 449F3). FT-IR spectra of PVA and crPVA thin films were obtained using a Bruker Vertex 70 spectrometer in ATR mode.

The transistor's electrical characterization was carried out at room temperature in air. Output and transfer curves were obtained using a source-measurement unit Keithley 2400C (D-S electrodes) coupled with an electrometer Keithley 6517A (S-G electrodes). Frequency response measurements were performed using the circuit shown in Fig. S1. An Autolab PGSTAT302 equipped with a FRA32M module was used for impedance spectroscopy. We fabricated and characterized 12 transistors and 8 of them exhibited equivalent performances, presented in this work.

\section{Results and discussion}

As discussed before, the intermediate electrode is key to the good performance of the VOFET, electrical transparency must be high without significant increase in $R_{s h}$. As deposited $R_{s h}$ for different AgNWs layers are presented in Table S1 (Supplementary data). In order to obtain low $\mathrm{R}_{\mathrm{sh}}$, the films were annealed on a hot plate in air. The annealing temperature of $120{ }^{\circ} \mathrm{C}$ was chosen considering the thermal stability of the dielectric layer, Fig. S2. $R_{s h}$ as a function of the annealing time and number of AgNWs layers are presented in Fig. 2 and Fig. S3 respectively.

As can be seen in Fig. 2, 4 layers is a good compromise between random meshes and conductivity. Fig. 2 (a) shows that $R_{\text {sh }}$ of asdeposited AgNWs is about $114.7 \pm 1.4 \Omega / \mathrm{sq}$, but after $40 \mathrm{~min}$ at $120{ }^{\circ} \mathrm{C}$ this value decreases more than $70 \%$ to $28.2 \pm 1.5 \Omega$ /sq. The increase in conductivity after annealing is attributed to the better contact and partial fusion between the nanowires [21], confirmed by SEM images shown in Fig. 2 (b) when compared with pristine AgNWs (without annealing), Fig. 2 (c). Moreover, using Image J software in Fig. 2 (b) we found that $30 \%$ of cr-PVA surface area is covered by AgNWs. This covering is heterogeneous as seen in Fig. 2 (d), with holes between 2 and $5 \mu \mathrm{m}$.

After the optimized annealing is performed $\left(120{ }^{\circ} \mathrm{C}\right.$ during $40 \mathrm{~min}$ ), the surface roughness root mean square (rms) is $70 \pm 20 \mathrm{~nm}$ as can be seen in Fig. 2 (e) and (f), while the resistance of a $2.5 \mathrm{~cm} \times 2.5 \mathrm{~cm}$ AgNWs electrode on cr-PVA is $22.4 \Omega$, Fig. 2 (g). Our morphological analyses indicate a fill factor (FF) of $\sim 0.70$ for the AgNWs electrodes considering the optimized parameters (number of AgNWs layers and annealing). Note that this high FF value was obtained keeping a high lateral conductivity, which is not commonly observed for other conventional intermediate electrodes in VOFETs [9-11,17]. Furthermore, considering the VOFET design rules from Ref. [22], the distance between the nanowires reported corresponds to the diameter (D) of the holes in the electrode while the rms value corresponds to the height $(\mathrm{h})$, leading to an aspect ratio h/D low enough for high on/off ratios.

VOFETs were fabricated using the optimized AgNWs intermediate electrode. The device electrical response is presented in Fig. 3. In the polarization condition used the intermediate electrode (AgNWs) acts as electron source and the top electrode ( $\mathrm{Al}$ ) as electron drain. Output characteristics $\left(J_{D S}-V_{D S}\right)$ for positively biased gate $\left(V_{G S}\right)$ are shown in Fig. 3 (a). As can be seen $J_{D S}$ increases as $V_{D S}$ and $\mathrm{V}_{\mathrm{GS}}$ are increased. The threshold voltage $\left(\mathrm{V}_{\mathrm{T}}\right)$ as shown in Fig. 3 (b) is found to be $1.06 \mathrm{~V}$. From Fig. 3 (c) the channel current density in the on-state $\left(\mathrm{V}_{\mathrm{GS}}=2 \mathrm{~V}\right)$ is about $2.5 \times 10^{-3} \mathrm{~A} / \mathrm{cm}^{2}$ while the channel current density in the off-state $\left(\mathrm{V}_{\mathrm{GS}}=0 \mathrm{~V}\right)$ is about $5.0 \times 10^{-7} \mathrm{~A} / \mathrm{cm}^{2}$ resulting in an on/off ratio of $5 \times 10^{3}$.

The leakage current density is similar to the channel current density found in the off-state $\left(\mathrm{V}_{\mathrm{GS}}=0 \mathrm{~V}\right)$. Nevertheless, the use of cr-PVA as dielectric has advantages, such as a low production cost and low capacitance $[11,20]$. Since the parasitic capacitance can be reduced, the low gate capacitance acts as a complementary factor to other two requirements for high switching frequencies in fieldeffect transistors: efficient charge transport in the semiconductor and small channel length [23]. The main source of parasitic capacitance expected in VOFETs is from gate-source overlap that

(a)

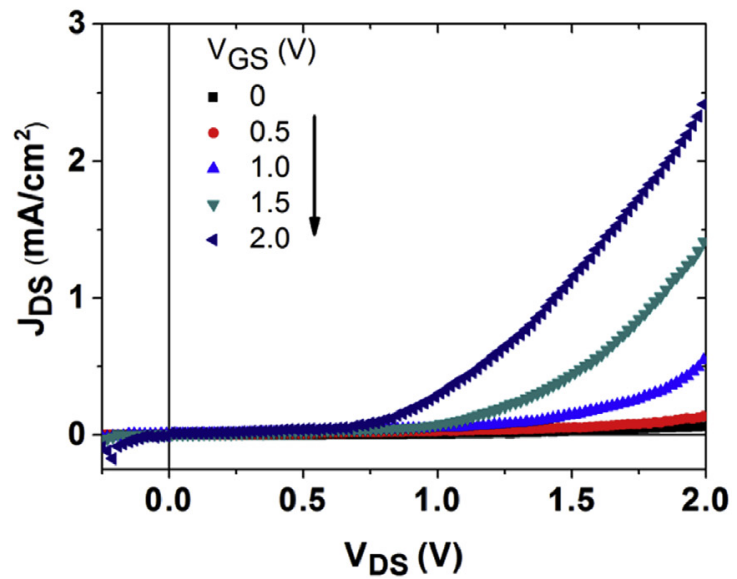

(b)

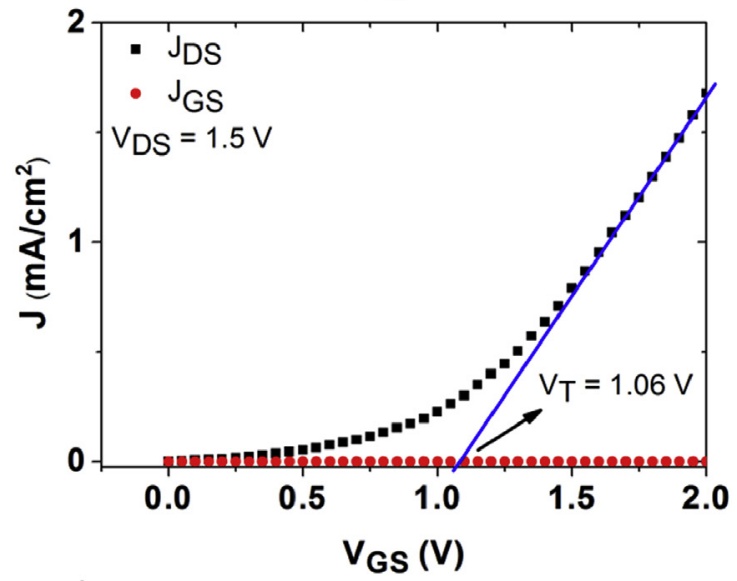

(c)

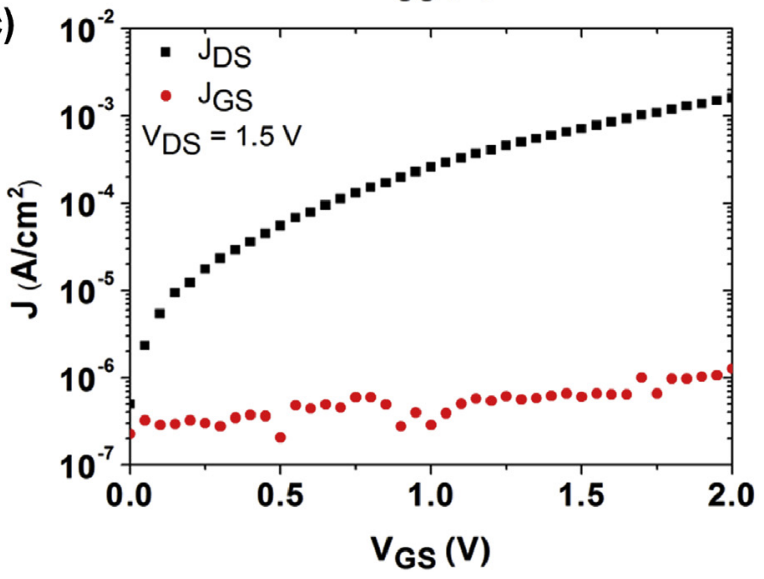

Fig. 3. (a) Output characteristics; (b) transfer characteristics $\left(V_{D S}=1.5 \mathrm{~V}\right)$ in linear and (c) monolog plots of the $\mathrm{Al} / \mathrm{cr}-\mathrm{PVA} / \mathrm{AgNWs} / \mathrm{C}_{60} / \mathrm{Al}$ VOFET. $\mathrm{V}_{\mathrm{T}}$ is the threshold voltage. 
does not contribute to drain current [15]. VOFETs have a main advantage, the small channel length determined by the semiconductor thickness, opening the possibility for a fast switching performance as will be shown. The combination of ultra-short channel length and high electric fields leads to remarkable current densities under low supply voltages, as seen in Fig. 3.

The exponential dependence of JDS on $V_{G S}$ observed in Fig. 3 (a) is an evidence of the total current being limited by interface processes, possibly as a consequence of the potential barrier between the source electrode and semiconductor layer [10]. When the device is in the off-state, the injection barrier between $\mathrm{AgNW}$ and $\mathrm{C}_{60}$ is approximately $0.4 \mathrm{eV}$ [24], in this case charges are extracted from the active layer only due to the applied drain-source voltage presenting similarity to a diode structure where contact limited (CL) regime is expected [22], as shown in Fig. 4 (a). With the device in the on-state, negative charges are accumulated in the voids of the source electrode (AgNWs) creating a virtual contact that induces positive charges in the $\mathrm{C}_{60}$ close to AgNWs interface [22] decreasing the electron injection barrier from the AgNWs to $C_{60}$.

In this configuration, the channel current can be affected by the gate bias where the device behaves according to space charge limited current (SCLC) $[22,25]$. Under SCLC regime, the channel current follows the Mott-Gurney law where $J_{\text {on }} \alpha \mathrm{V}_{\mathrm{DS}}^{2}[22,25,26]$, as shown in Fig. S4. The scaling exponent of 2.5 obtained in Fig. S4 can be associated to electron traps within the semiconductor that influence the SCLC regime due to the Poole-Frenkel effect [26], Fig. 4 (b) process I. However, if the gate-source voltage is not high enough to create an ohmic contact at the interface, charges can be also injected by Fowler-Nordheim tunneling [27], Fig. 4 (b) process II.

In addition to electron traps within semiconductor, in fact the main charge traps in our devices are probably from hydroxyl and ketone groups in the cr-PVA layer [20]. These groups were known to act as electron traps, especially the ketone groups [28]. The PVA molecular structure is basically composed by carbon chains with large amounts of hydroxyl end groups. The crosslinking induced by ammonium dichromate is based on the interaction of the chromium ions with the PVA molecular structure that results in carbon double bonds, responsible for the increased resistivity of the dielectric. This reaction as observed from FT-IR spectra shown in (a)

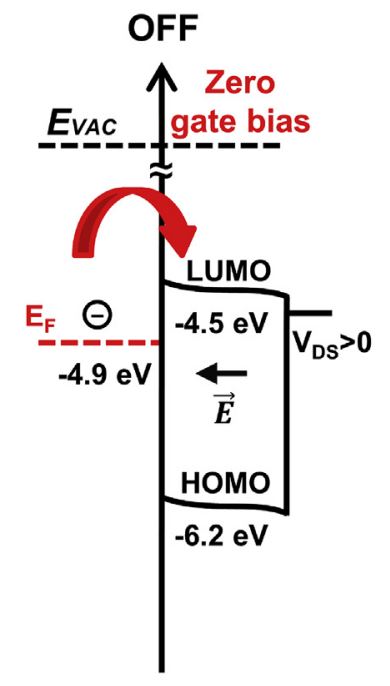

(b)

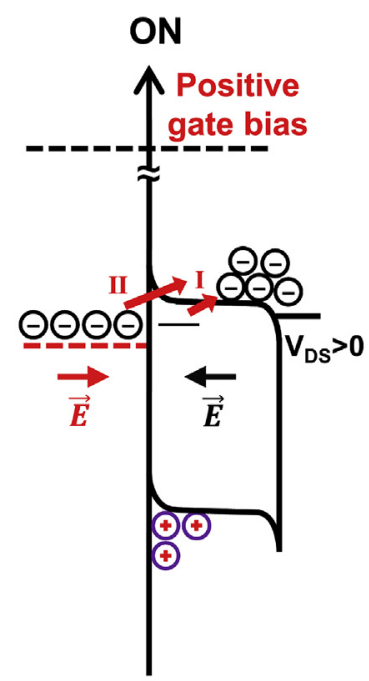

\section{AgNWs $\mathrm{C}_{60} \quad \mathrm{Al}$}

Fig. 4. Schematic energy diagram of $A g N W s / C_{60} / A l$ interfaces, for: (a) zero gate bias; (b) positive gate bias. (a)
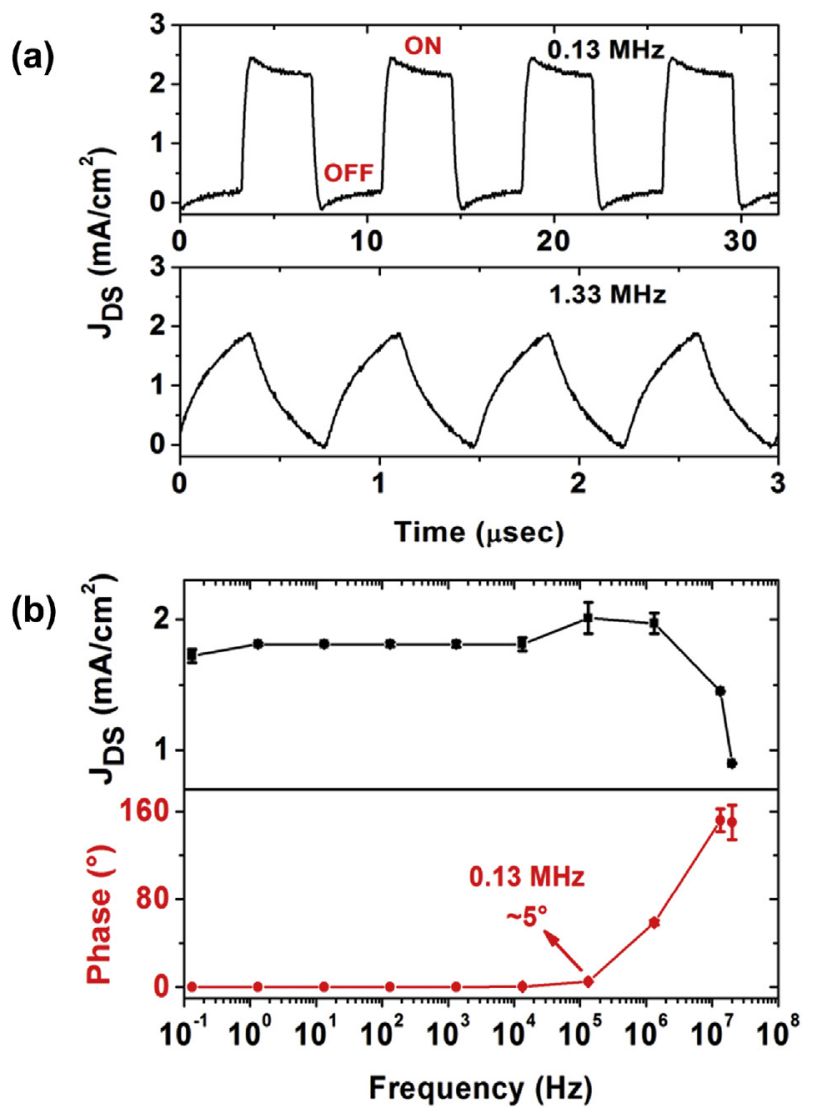

Fig. 5. Dynamic response of the $\mathrm{Al} / \mathrm{cr}-\mathrm{PVA} / \mathrm{AgNWs} / \mathrm{C}_{60} / \mathrm{Al}$ VOFET: (a) $0.13 \mathrm{MHz}$ and $1.33 \mathrm{MHz}$ frequencies gate modulation; (b) modulated channel current density and phase in the on-state as a function of input frequency.

Fig. S5 also produces ketones groups from the oxidation of the hydroxyl groups [29].

Fig. 5 shows the dynamic response of the VOFET to a squarewave input signal applied in the gate electrode with amplitude of $1.5 \mathrm{~V}$ and offset $0.75 \mathrm{~V}$ at different frequencies. $\mathrm{V}_{\mathrm{DS}}$ was fixed at a DC voltage of $1.5 \mathrm{~V}$. As can be seen in Fig. 5 (a), at frequencies up to $0.13 \mathrm{MHz}$ the modulated channel current density follows the input square-wave signal. From fitting procedures, the response time under this modulation is $\tau_{\text {rise }}^{\text {out }}=0.45 \mu \mathrm{s}$ and $\tau_{\text {fall }}^{\text {out }}=0.55 \mu \mathrm{s}$. Increasing the frequency to $1.33 \mathrm{MHz}$, the device current density

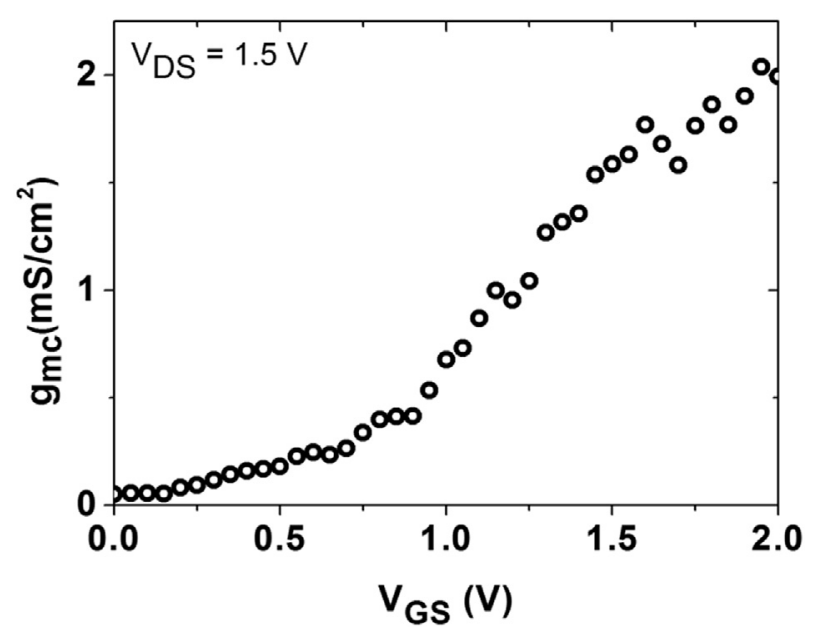

Fig. 6. Specific transconductance of the $\mathrm{Al} / \mathrm{cr}-\mathrm{PVA} / \mathrm{AgNWs} / \mathrm{C}_{60} / \mathrm{Al}$ VOFET at $\mathrm{V}_{\mathrm{DS}}=1.5 \mathrm{~V}$. 
Table 1

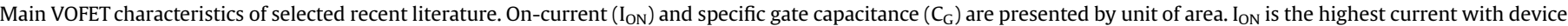
at on-state.

\begin{tabular}{|c|c|c|c|c|c|c|}
\hline Intermediate electrode & Method & Active layer & $\mathrm{I}_{\mathrm{ON}}\left(\mathrm{mA} / \mathrm{cm}^{2}\right)$ & $\mathrm{C}_{\mathrm{G}}\left(\mathrm{nF} / \mathrm{cm}^{2}\right)$ & On/off & Ref. \\
\hline Sn & Thermal evaporation & CuPc & 0.175 & $\mathrm{a}$ & a & [10] \\
\hline $\mathrm{Al}$ & Thermal evaporation & $\mathrm{C}_{60}$ & 0.013 & 27 & $<10^{2}$ & [11] \\
\hline CNTs & Vacuum filtration & DNTT & 110 & 354 & $>10^{4}$ & {$[12]$} \\
\hline Graphene & CVD & P3HT & 3400 & $\sim 210$ & $>10^{3}$ & [15] \\
\hline ITO & Sputtering & ITO & $\sim 8$ & $\sim 7000$ & $\sim 10^{5}$ & {$[17]$} \\
\hline $\mathrm{Ag} / \mathrm{Au}$ NWs & Self-assembly & N2200 & $>1$ & a & $\sim 10^{5}$ & [19] \\
\hline $\mathrm{Au}$ & Block-copolymer & $\mathrm{N} 2200$ & $\sim 10$ & a & $10^{3}$ & [32] \\
\hline AgNWs & Mayer rod-coating & $\mathrm{C}_{60}$ & 2.5 & 5 & $5 \times 10^{3}$ & This work \\
\hline
\end{tabular}

${ }^{\text {a }}$ Not specified in the original work.

does not follow the input modulation anymore. In Fig. 5 (b) the modulated channel current density and its phase as a function of the input frequency is presented. Up to $0.13 \mathrm{MHz}$ the modulated channel current density is basically the same whereas the phase starts to change from $0^{\circ}$ to $\sim 5^{\circ}$, which is still acceptable for electronic circuit application. However, for higher frequencies the modulated current decreases and there is a clear change in the phase showing that our devices have a switching limitation of about $10^{5} \mathrm{~Hz}$.

The switching speed of the transistor and its limitations shown in Fig. 5 are mainly related to the gate capacitance. As can be seen in Fig. S6 (a), the specific gate capacitance measured by impedance spectroscopy is between 2 and $5 \mathrm{nF} / \mathrm{cm}^{2}$. However, for frequencies higher than $10^{5} \mathrm{~Hz}$ the specific gate capacitance decreases significantly and the switching performance of the transistor starts to be limited by the sheet resistance of the intermediate electrode. Considering an ideal field-effect transistor, the maximum frequency of operation (where $\mathrm{I}_{\mathrm{DS}}=\mathrm{I}_{\mathrm{GS}}$ ) is defined by a large transconductance and low gate capacitance, $\mathrm{f}_{\mathrm{T}}=\mathrm{g}_{\mathrm{m}} /\left(2 \pi \mathrm{C}_{\mathrm{G}}\right)$ [23]. In our case, the specific transconductance $\left(g_{\mathrm{mc}} \equiv \mathrm{g}_{\mathrm{m}} /\right.$ area $)$ at $\mathrm{V}_{\mathrm{GS}}$ and $\mathrm{V}_{\mathrm{DS}}$ of $1.5 \mathrm{~V}$ is $\sim 1.5 \mathrm{mS} / \mathrm{cm}^{2}$, as shown in Fig. 6. Assuming the specific gate capacitance of $5 \mathrm{nF} / \mathrm{cm}^{2}$ at $1 \mathrm{~Hz}$ and the specific transconductance of $1.5 \mathrm{mS} / \mathrm{cm}^{2}$, we project a cut-off frequency of $\sim 50 \mathrm{kHz}$, close to the frequency where the phase starts to increase in Fig. 5 (b).

The frequency response of our devices could be improved even further by reducing the parasitic gate capacitance or using oxide dielectrics with ultra-low gate capacitance $(<10 \mathrm{pF})$ [30]. However, oxides are not compatible with a full organic electronics perspective. On the other hand, hybrid dielectrics (organic-inorganic) are promising candidates [31].

Our VOFET based on the optimized AgNWs intermediate electrode using Mayer rod-coating presented performance comparable with those published so far in the recent literature, as can be seen in Table 1. The channel current has a better modulation compared to previous VOFET with similar materials but with ultra-thin $(\sim 20 \mathrm{~nm})$ $\mathrm{Al}$ evaporated film as intermediate electrode [11]. While our device exhibited an on/off ratio of $5 \times 10^{3}$ the VOFET reported by Rossi et al. shows on/off ratios $<10^{2}$. The reason may be related to the porous nature of the AgNWs electrodes and thus higher FF and better electric field permeation.

In addition, our VOFET showed a sub- $1 \mu$ s switching at low voltages opening possibilities for industrial circuit applications, for example, as drivers of active matrix OLED pixels [33]. Furthermore, the Mayer rod-coating deposition method presents wide compatibility with industrial-scale production at low-cost and can be also used in flexible substrates with low processing temperatures.

\section{Conclusion}

In summary, in this work we demonstrated an easy to prepare low-cost VOFET with silver nanowires as intermediate grid electrodes. We systematically investigated the deposition parameters of the AgNWs grid using Mayer rod-coating method. Applying the optimized parameters a VOFET was produced and characterized. The device exhibits a good performance with a high output density of $2.5 \mathrm{~mA} / \mathrm{cm}^{2}$ and on/off ratio of $5 \times 10^{3}$ with supply voltages up to $2 \mathrm{~V}$. Moreover, this device presented a threshold voltage of about $1 \mathrm{~V}$ and a good switching performance up to $0.13 \mathrm{MHz}$.

\section{Acknowledgments}

We gratefully acknowledge FAPESP (grants: 2011/21830-6, 2013/07296-2, 2013/09963-6) and CAPES for providing financial support. We thank Dr Silvia L. Fernandes for assistance with the Scanning Electron Microscope (SEM). We also thank Prof Dr José $\mathrm{H}$. D. Silva and Prof Dr Luis V. A. Scalvi for providing the evaporation systems.

\section{Appendix A. Supplementary data}

Supplementary data related to this article can be found at http:// dx.doi.org/10.1016/j.orgel.2017.08.011.

\section{References}

[1] T.M. Barnes, M.O. Reese, J.D. Bergeson, B.A. Larsen, J.L. Blackburn, M.C. Beard, J. Bult, J. van de Lagemaat, Adv. Energy Mater. 2 (2012) 353.

[2] A. Ansón-Casaos, R. Mis-Fernández, C.M. López-Alled, E. Almendro-López, J. Hernández-Ferrer, J.M. González-Domínguez, M.T. Martínez, Chem. Eng. Sci. 138 (2015) 566.

[3] Z. Liu, P. You, C. Xie, G. Tang, F. Yan, Nano Energy 28 (2016) 151.

[4] X. Lin, S. Chen, J. Yu, K. Wang, D. Luo, X. Sun, X. Zhang, Thin Solid Films 624 (2017) 54.

[5] S. Ye, A.R. Rathmell, Z. Chen, I.E. Stewart, B.J. Wiley, Adv. Mater. 26 (2014) 6670.

[6] E. Jung, C. Kim, M. Kim, H. Chae, J.H. Cho, S.M. Cho, Org. Electron. 41 (2017) 190.

[7] B. Wei, X. Wu, L. Lian, S. Yang, D. Dong, D. Feng, G. He, Org. Electron. 43 (2017) 182.

[8] K.-M. Chiang, Z.-Y. Huang, W.-L. Tsai, H.-W. Lin, Org. Electron. 43 (2017) 15.

[9] L. Ma, Y. Yang, Appl. Phys. Lett. 85 (2004) 5084.

[10] A. Kvitschal, I. Cruz-Cruz, I.A. Hümmelgen, Org. Electron. 27 (2015) 155.

[11] L. Rossi, K.F. Seidel, W.S. Machado, I.A. Hümmelgen, J. Appl. Phys. 110 (2011) 094508.

[12] M.A. McCarthy, B. Liu, A.G. Rinzler, Nano Lett. 10 (2010) 3467.

[13] M.G. Lemaitre, E.P. Donoghue, M.A. McCarthy, B. Liu, S. Tongay, B. Gila, P. Kumar, R.K. Singh, B.R. Appleton, A.G. Rinzler, ACS Nano 6 (2012) 9095.

[14] K. Kim, T.H. Lee, E.J.G. Santos, P.S. Jo, A. Salleo, Y. Nishi, Z. Bao, ACS Nano 9 (2015) 5922.

[15] Y. Liu, H. Zhou, N.O. Weiss, Y. Huang, X. Duan, ACS Nano 9 (2015) 11102.

[16] A.J. Ben-Sasson, E. Avnon, E. Ploshnik, O. Globerman, R. Shenhar, G.L. Frey, N. Tessler, Appl. Phys. Lett. 95 (2009) 213301.

[17] W. Hu, Z. Zheng, J. Jiang, Org. Electron. 44 (2017) 1.

[18] Y. Hsu, X. Fang, L.A. Wang, H.-W. Zan, H.-F. Meng, S.-H. Yang, Org. Electron. 15 (2014) 3609.

[19] A.J. Ben-Sasson, D. Azulai, H. Gilon, A. Facchetti, G. Markovich, N. Tessler, ACS Appl. Mater. Interfaces 7 (2015) 2149.

[20] A.R.V. Benvenho, W.S. Machado, I. Cruz-Cruz, I.A. Hümmelgen, J. Appl. Phys. 113 (2013) 214509.

[21] A.R. Madaria, A. Kumar, F.N. Ishikawa, C. Zhou, Nano Res. 3 (2010) 564. 
[22] A.J. Ben-Sasson, N. Tessler, J. Appl. Phys. 110 (2011) 044501.

[23] U. Zschieschang, R. Hofmockel, R. Rödel, U. Kraft, M.J. Kang, K. Takimiya, T. Zaki, F. Letzkus, J. Butschke, H. Richter, J.N. Burghartz, H. Klauk, Org. Electron. 14 (2013) 1516.

[24] D. Wang, W. Zhou, H. Liu, Y. Ma, H. Zhang, Nanotechnology 27 (2016) 335203.

[25] Y. Preezant, N. Tessler, J. Appl. Phys. 93 (2003) 2059.

[26] P.N. Murgatroyd, J. Phys. D. Appl. Phys. 3 (1970) 151

[27] M.H. Boratto, R.A. Ramos Jr., M. Congiu, C.F.O. Graeff, L.V.A. Scalvi, Appl. Surf. Sci. 410 (2017) 278

[28] M.-H. Yoon, C. Kim, A. Facchetti, T.J. Marks, J. Am. Chem. Soc. 128 (2006)
12851.

29] L. Grimm, K.-J. Hilke, E. Scharrer, J. Electrochem. Soc. 130 (1983) 1767.

[30] D. Kälblein, H. Ryu, F. Ante, B. Fenk, K. Hahn, K. Kern, H. Klauk, ACS Nano 8 (2014) 6840.

31] M. de Pauli, U. Zschieschang, I.D. Barcelos, H. Klauk, A. Malachias, Adv. Electron. Mater. 2 (2016) 1500402.

[32] M. Greenman, A.J. Ben-Sasson, Z. Chen, A. Facchetti, N. Tessler, Appl. Phys. Lett. 103 (2013) 073502.

[33] A.J. Ben-Sasson, M. Greenman, Y. Roichman, N. Tessler, Isr. J. Chem. 54 (2014) 568. 